\title{
Guest editorial for the special section on "Technology acceptance, usage, and competitive advantage"
}

\author{
Devaki Rau • Thorvald Haerem • Gautam Ray • \\ Wei Zheng
}

Published online: 10 October 2009

(C) Springer Science + Business Media, LLC 2009

A central question in the strategic management literature is one of how organizations achieve and maintain sustainable competitive advantage. While scholars in this area have explored this issue from many different perspectives, our understanding of the relationship between technology acceptance, usage, and competitive advantage is still incomplete. The papers in this special section (some of which were originally presented in a session on this topic in INFORMS 2008) focus on this issue. They present studies situated in an international context, underscoring the importance of technology to competitive advantage across different national contexts. They examine a rich array of technologies or technological infrastructures that have a bearing on the success of individuals and organizations, pointing to the complex relationship between technology and business outcomes. We present a brief summary of the papers below.

The study "From IT deployment capabilities to competitive advantage: An exploratory study in China" by Jun Tian,

D. Rau $(\bowtie) \cdot$ W. Zheng

Northern Illinois University,

DeKalb, IL, USA

e-mail: drau@niu.edu

W. Zheng

e-mail: wzheng@niu.edu

T. Haerem

Norwegian School of Management, Norway, and University of California,

Irvine, CA, USA

e-mail: thorvald.harem@bi.no

G. Ray

University of Minnesota,

Minneapolis, MN, USA

e-mail: rayxx153@umn.edu
Kanliang Wang, Yan Chen, and Bjorn Johansson uses a survey of Chinese firms to examine how organizations can deploy acquired information technologies to support and shape business strategies and value chain activities. The paper identifies three building blocks of IT deployment, namely strategic IT flexibility, business-IT partnership, and business - IT alignment, and empirically examines how these three constructs directly or indirectly influence competitive advantage.

The study "ICT infrastructure for innovation" by Bendik Bygstad builds on a case study of the Norwegian company, Norwegian Corp., to examine how the concept of an enterprise service bus, applied at different levels, can provide insights into the innovation process both within and across different business units of an organization. The study illustrates how technologies can influence the development of organizational structures.

The study "Knowledge management technology for organized crime assessment" by Petter Gottschalk presents a knowledge management technology stage model. This study examines how police organizations use information and communication technologies in intelligence and investigative work, and highlights the challenges these organizations face in applying and using new technologies to improve their functioning.

The study "Successful and unsuccessful multicommunication episodes: Engaging in dialogue or juggling messages?" by Jeanine W. Turner and N. L. Reinsch uses a critical incident technique to explore multicommunicating by individuals. Turner and Reinsch define multicommunicating as the act of engaging in more than one conversation at a time, and find that some technology pairings appear more conducive to multicommunicating than others. The respondents in their study provide a number of reasons why some episodes of multicommunicating are successful while others are not. 
The study "Applying an organizational learning perspective to new technology deployment by technological gatekeepers: A theoretical model and key issues for future research" by Devaki Rau and Thorvald Haerem identifies factors that influence technological gatekeepers' decisions about exploring or exploiting the routines associated with a new technology. This study draws on the organizational learning, expertise, and cognitive styles literatures to identify issues of interest for micro-level research on new technology deployment in organizations.

The papers in this special section have some interesting similarities and differences. Three of these studies examine the relationship between technology acceptance, usage, and competitive advantage at an organizational level, while two examine this relationship at the individual level. All of these studies examine the relationship between technology acceptance, usage, and competitive advantage in different contexts. Gottschalk's study, for example, examines police organizations worldwide, Tian et al.'s study surveys multiple Chinese firms, and Bygstad's study examines a single Norwegian organization in depth. At the individual level, Turner and Reinsch's study examines individuals based in the U.S., but differing in their countries of origin. Rau and Haerem's study looks at a very specific context, that of a technological gatekeeper charged with introducing a new technology into an organization. Perhaps most interestingly, all of these studies draw on different literatures (strategy, law, communication, organizational learning, expertise, and cognitive styles) to examine the relationship between technology and competitive advantage.

When considered together, these similarities and differences point to two interesting issues and directions for future research. First, there is clearly tremendous scope for cross-level, crosscontextual, and cross-disciplinary research on the relationship between technology acceptance, usage, and competitive advantage. Studies that examine, for instance, how individual level decisions influence technology usage within organizations can contribute to our understanding of the topic of this special section. Replicating such studies in different contexts, and / or drawing on different disciplines to examine this issue, will lead to more insights on this topic.

Second, many of the papers in this special section suggest that, quite often, the new technology deployed in organizations may have unanticipated consequences. Thus, for instance, organizations may find that technology does not lead to competitive advantage if it does not match other components of the organization's strategy (Tian et al.) or structure (Gottschalk). New technologies may enable organizational diversification, but at the same time constrain the type of diversification open to the organization (Bygstad). Individuals may use new technologies to improve productivity, but may also experience communication failures when attempting to use many technologies simultaneously (Turner and Reinsch). Organizations may introduce a new technology in an attempt to develop a new source of competitive advantage, but instead end up refining their existing sources of competitive advantage, depending on the decisions made by the technological gatekeeper (Rau and Haerem). These studies suggest that it is not only important for us to understand how technology may lead to competitive advantage, but it is also critical to explore how the current strategy and structure of an organization (including the characteristics of the individuals involved) may constrain the effectiveness of a new technology.

We hope that the issues examined in this special section spark readers' interest in this topic and stimulate future research in this area.

\section{References}

Bygstad, B. (forthcoming in 2010). ICT infrastructure for innovation. Information Systems Frontiers. doi:10.1007/s10796-009-9169-9

Gottschalk, P. (forthcoming in 2010). Knowledge management technology for organized crime assessment. Information Systems Frontiers. doi:10.1007/s10796-009-9178-8

Rau, D., \& Haerem, T. (forthcoming in 2010). Applying an organizational learning perspective to new technology deployment by technological gatekeepers: A theoretical model and key issues for future research. Information Systems Frontiers. doi:10.1007/s10796-009-9194-8

Tian, J., Kanliang, W., Yan, C., \& Johansson, B. (forthcoming in 2010). From IT deployment capabilities to competitive advantage: An exploratory study in China. Information Systems Frontiers, Information Systems Frontiers. doi:10.1007/s10796-009-9182-Z

Turner, J. W., \& Reinsch, N. L. (forthcoming in 2010). Successful and unsuccessful multicommunication episodes: Engaging in dialogue or juggling messages? Information Systems Frontiers. doi:10.1007/s10796-009-9175-y

Devaki Rau earned her Ph.D. in management at the University of Minnesota and is currently a faculty member in the Department of Management at Northern Illinois University. Her research focuses on the recognition and utilization of expertise in teams and individuals, managerial decision making, and top management teams. She has published her research in journals such as the Journal of Applied Psychology, Small Group Research, and Journal of Business Research. She worked as a business development executive in CMC Ltd., a software development and maintenance firm in Bangalore, India, prior to obtaining her Ph.D.

Thorvald Haerem earned his Ph.D. at Copenhagen Business School in Denmark and is currently a faculty member at the Norwegian School of Management. His research interests include technology, organizational forms, decision making, and expertise. He has published his research in journals such as the Journal of Applied Psychology and the International Journal of Organizational Analysis. $\mathrm{He}$ is the co-founder and a board member of Compello Software, a major actor in the Scandinavian market for Purchase to Pay solutions. 
Gautam Ray earned his Ph.D. in Information Systems from the Ohio State University and is currently a faculty member in the Information Systems Department in the Carlson School of Management at the University of Minnesota. His research interests are in the area of impact of information technology on firms and markets, specifically about how firms make choices to take advantage of opportunities provided by information technology. He has published his research in journals such as Management Science, Marketing Science, MIS Quarterly, and the Strategic Management Journal. He worked as a business development executive in CMC Ltd., a software development and maintenance firm in Chennai, India, prior to obtaining his Ph.D.

Wei Zheng earned her Ph.D. in Human Resource Development from the University of Minnesota and is currently a faculty member in the department of Counseling, Adult, and Higher Education at Northern Illinois University. Her research interests include social dynamics of innovation, knowledge management, and organizational learning. She has worked as a learning and performance consultant with several companies such as Medtronic, Thomson, and Wal-Mart. 